\title{
MALO ZNAN DVOZBORSKI CIKLUS HIMNUSOV IZ OK. 1600
}

\author{
KLEMEN GRABNAR \\ Muzikološki inštitut ZRC SAZU
}

Izvleček: Ena izmed kornih knjig graškega izvora, ohranjenih $v$ Ljubljani (SI-Lnr, MS 343), med drugim vsebuje 31 večerničnih himnusov Francesca Stivorija. Ti so ohranjeni le v omenjenem viru. Stivorijevi himnusi tvorijo cikel za celotno liturgično leto in so del dolge tradicije polifonih uglasbitev, ki temeljijo na koralnih melodijah, vendar so napisani za večjo zasedbo kot običajno, in sicer za osem glasov, razdeljenih v dva zbora. Polifoni himnusi iz druge polovice 16. stoletja, ki so bili del repertoarja graškega dvora, v liturgičnem smislu niso bili zastareli. Zato se zdi, da je Stivori svoj cikel skomponiral, da bi zadovoljil estetske potrebe nadvojvode Ferdinanda, ki je bil izjemno naklonjen večzborski glasbi.

Ključne besede: Francesco Stivori, himnusi, dvozborska glasba, korna knjiga, Notranja Avstrija
Abstract: An early-seventeenth-century choirbook originating from Graz surviving in Ljubljana (SI-Lnr, MS 343) contains alongside other compositions thirty-one hymns by Francesco Stivori uniquely known from this source. Stivori's hymns form a cycle for the entire liturgical year. They follow a long tradition of polyphonic settings based on plainsong melodies, although they are set for a larger performing group than usual - eight voices distributed in two choirs. Polyphonic hymn settings in use earlier at the Graz court were not liturgically obsolete. It seems, therefore, that Stivori composed his own cycle to cater for the personal aesthetic needs of Archduke Ferdinand, who greatly favoured polychoral music.

Keywords: Francesco Stivori, hymns, doublechoir music, choirbook, Inner Austria

Ciklusom himnusov lahko sledimo že vse od 14. stoletja dalje. Za prvega velja deset triglasnih himnusov iz rokopisa iz Apta s konca 14. stoletja. Ti so tvorili ciklus uglasbitev za vse večje praznike liturgičnega leta, ki pa se do danes ni ohranil. Zdi se, da je bil prvi pomemben ciklus, ki je bil delo enega samega skladatelja in ni bil razširjen le na lokalni ravni, Dufayev, nastal verjetno med letoma 1433 in $1435 .{ }^{1} \mathrm{~V}$ 15. pa tudi v 16. stoletju je bilo zelo pogosto kompiliranje ciklusov, pri katerem so bile združene uglasbitve različnih himnusov uveljavljenih in manj uveljavljenih, lokalnih skladateljev. Tovrstne kompilacije

Razprava je nastala v okviru raziskovalnega programa »Raziskave slovenske glasbene preteklosti « (P6-0004), ki ga financira Javna agencija za raziskovalno dejavnost Republike Slovenije.

1 Anderson idr., »Hymn«. 
so bile prilagojene za lokalno liturgijo. Občutno porast komponiranja ciklusov himnusov zaznamo šele od druge tretjine 16. stoletja naprej, ko je bilo uveljavljeno štiriglasje. Vrhunec tovrstne ustvarjalnosti pa je bil dosežen proti koncu 16. in v prvih letih 17. stoletja. V tem času so nastali ciklusi - praviloma štiriglasni - izpod peresa skladateljev, kot so Orlando di Lasso, Tomás Luis de Victoria, Giaches de Wert, Costanzo Porta, Orazio Vecchi in Giovanni Pierluigi da Palestrina. ${ }^{2}$ Med ciklusi iz omenjenega časa pa zaradi zasedbe izstopajo uglasbitve himnusov organista na graškem dvoru Francesca Stivorija - vsi himnusi so namreč napisani za zasedbo osem glasov, razdeljenih v dva zbora. Stivorijevi himnusi še niso bili deležni obsežnejše obravnave, ${ }^{3}$ zato skuša pričujoči prispevek nakazati, da si v sklopu glasbene zgodovine himnusa zaslužijo večjo pozornost.

Na graškem dvoru je bila ena izmed najuglednejših glasbenih mest služba dvornega organista. Navadno so bili organisti tudi dobri skladatelji; med temi so najbolje poznani denimo Annibale Padovano, Francesco Rovigo in Giovanni Valentini. ${ }^{4}$ Leta 1602 je organist v tamkajšnji kapeli postal Francesco Stivori (ok. 1550-1605). Pogosto se kot kraj njegovega rojstva omenjajo Benetke, ${ }^{5}$ vendar ohranjeno dokumentarno gradivo nakazuje, da se je rodil v Veroni. ${ }^{6}$ Temu v prid pričajo tudi njegova posvetila vidnim veronskim glasbenim mecenom kar nekaj tiskanih glasbenih zbirk, denimo Mariu Bevilacqui in Alessandru Giustiju. ${ }^{7}$ Prav tako sta pomenljiva izid njegove zbirke Sacrae cantiones quaternis paribus voce decantandae v Veroni leta 1595 in njegovo uredništvo zbirke madrigalov za pet glasov veronskega organista Paola Bellasia. ${ }^{8}$ Pred odhodom v Gradec je Stivori več kot dvajset let služil kot mestni organist v Montagnani pri Padovi. ${ }^{9}$ Kot je bilo ugotovljeno nedavno, je bil njegov ekonomski položaj v Montagnani zelo slab. ${ }^{10}$ Kot nakazujejo nekatera posvetila tiskanih zbirk beneškim veljakom, je morda skušal pridobiti boljšo službo v kateri izmed številnih beneških glasbenih ustanov. Njegov finančni položaj se je korenito izboljšal šele po tem, ko je postal organist na graškem dvoru. Tam

2 Ibid., 26-27.

3 Nekaj vrstic sta jim namenila denimo Höfler, Glasbena umetnost pozne renesanse, 34-35, in Kokole, »From Graz«, 352-353. V prilogi slednjega prispevka (str. 359-373) sta dostopni tudi transkripciji dveh Stivorijevih himnusov iz obravnavanega ciklusa: Doctor egregie in Urbs beata Jerusalem. Oba himnusa je transkribiral avtor pričujočega članka.

4 Padovano (1527-1575) je na graškem dvoru deloval kot organist od leta 1565, leta 1570 pa je tam prevzel mesto vodje glasbene kapele. Rovigo (1541/2-1597) je bil organist v graški kapeli od leta 1582 do smrti nadvojvode Karla II. leta 1590. Valentini (1582/3-1649) pa je služboval kot organist v času nadvojvode Ferdinanda II., tj. od leta 1614 in se leta 1619, ko je bil Ferdinand izvoljen za cesarja, preselil na Dunaj. Federhofer, Musikpflege und Musiker, 103-110, 125-128 in 219-225.

5 Gl. na primer Gruber, »Stivori«, 684; Boisits, »Stivori«, 2314; Carideo, »Wiederentdeckte Kompositionen«, 64; Federhofer, Musikpflege und Musiker, 213.

6 Refatti, »Vorwort«, VIII.

7 Več gl. ibid.

8 Stivori, Sacrae cantiones quaternis paribus voce decantandae; Bellasio, Il quinto libro de madrigali a cinque. Gl. Einstein, »Italienische Musik und italienische Musiker «, 45.

9 Eitner, Biographisch-Bibliographisches Quellen-Lexikon, je v geslu o Stivoriju zmotno navedel, da leži Montagnana pri Milanu.

${ }^{10}$ Refatti, »Vorwort«, viII. 
je bil namreč s 45 goldinarji najbolje plačan glasbenik; njegova plača je bila celo višja od te, ki jo je prejemal vodja kapele Pietro Antonio Bianco. ${ }^{11}$

Stivori je bil najverjetneje učenec slovitega organista, skladatelja in založnika Claudia Merula, kar se domneva na podlagi posvetila njegove zbirke štiriglasnih ricercarjev iz leta 1589: »Al molto magnifico signore, patrone, precettore, \& protettor mio singularissimo il signor Claudio Merulo, organista del serenissimo Duca di Parma, \& di Piacenza. ${ }^{12} \mathrm{~V}$ preteklosti so ga pogosto označevali tudi kot učenca morda še bolj znamenitega beneškega skladatelja Giovannija Gabrielija, predvsem na podlagi posvetila tretje knjige štiriglasnih ricercarjev, capriccov in canzon Gabrieliju. ${ }^{13}$ Kot je trdil Federhofer, je zelo malo verjetno, da bi bil Stivori Gabrielijev učenec, saj ga je slednji v pismu iz leta 1604, naslovljenem na graškega svetnika dvorne komore Juliusa von Paara, označil kot »mio cordialissimo amico«, poleg tega je bil Stivori verjetno nekoliko starejši. ${ }^{14}$ Sodobniki, tako skladatelji kot tudi glasbeni teoretiki, so Stivorija kot glasbenika cenili. Tako ga je Costanzo Antegnati v svojem delu L'arte organica navajal kot enega izmed »authori illustri \& eccellentissimi «, ${ }^{15}$ Giovanni Maria Artusi pa ga je denimo omenil med »musici eccelenti «. ${ }^{16}$

Stivorijev glasbeni opus je precej obsežen. Obsega tri tiskane zbirke ricercarjev in sorodnih žanrov, sedem tiskanih zbirk madrigalov (te so bile precej vplivne in vključujejo tudi primere večzborskih dialogov) in nekaj madrigalov, objavljenih v antologijah, šest tiskanih zbirk Sacrarum cantionum ter liturgično glasbo, ohranjeno v rokopisih: dve maši, pet magnifikatov in cikel enaintridesetih himnusov. ${ }^{17}$ Nekaj njegovih del je tudi izgubljenih. $^{18}$

Edini vir Stivorijevega cikla himnusov je ena izmed Hrenovih kornih knjig, in sicer MS 343 iz Zbirke rokopisov, redkih in starih tiskov Narodne in univerzitetne knjižnice v

${ }^{11}$ Federhofer, Musikpflege und Musiker, 32.

${ }^{12}$ Stivori, Ricercari a quatro voci. Celotno besedilo posvetila se glasi: »Escono alle ftampe questi miei pochi Ricercari ricchi, \& adorni del nobiliffimo, \& famofiffimo fuo nome: non perche alla $V$. S. conuenga vn cofi rozo prefente, o perche io con fi rozo prefente defideri fignificarle la memoria, che indelebilmente conferuo de viui benefici, che da lei mi fono ftati fatti: ma perche, effondo frutti de fecondiffimi fuoi femi, al fuo cultore piu, che ad ogn'altro fi deuono; \& dal fuo cultore piu, che da ogni altro potranno effer contra ogni inimica tempefta defefi. Però la prego, che torcendo l'occhio dal donatore, \& dal dono le fia tanto a cuore la protettione di quefto mio, anzi di questo fuo parto, quanto farà fempre a cuore a me la fua falute. Et le bacio affettionatiffimo, \& reuerentiffimo le mani; dedicandole infieme con quefte faticuccie, anco me steffo. Di Montagnana il dì 15 di Giugno 1589.

Di V.S.M. Magnifica,

Scolare, \& Seruitore perpetuamente vbligato.

Francefco Stiuori."

${ }^{13}$ Stivori, Ricercari, capricci et canzoni a quattro voci.

${ }^{14}$ Federhofer, »Stivori«; Federhofer, Musikpflege und Musiker, 214.

${ }^{15}$ Antegnati, L'arte organica, [fol. 2r]. Stivorija je na tem mestu postavil v družbo Annibala Padovana, Claudia Merula, Andrea in Giovannija Gabrielija idr.

${ }^{16}$ Artusi, Seconda parte dell 'Artusi, 26. Ostali so še Alessandro Striggio, Andrea Gabrieli, Costanzo Porta, Claudio Merulo, Giovanni Pierluigi da Palestrina idr.

${ }^{17}$ Prim. seznam del v: Gruber, »Stivori«, 684-685.

${ }^{18}$ Npr. Lamentationes Ieremiae a 8, ki so omenjene v »Catalogus Librorum Aulicae Graecensis« iz leta 1672. Gl. Federhofer, Musikpflege und Musiker, 289. 
Ljubljani. Kodeks je izdelal graški dvorni basist in prepisovalec not Georg Kuglmann; ker so skladbe namenjene dvema zboroma, kodeks obstaja v dveh knjigah (glasovi vsakega izmed obeh zborov so zapisani v svoji knjigi). ${ }^{19}$ Rokopis je nastal na začetku 17. stoletja in izkazuje vsebinsko zasnovo, ki je postala na prehodu v 17. stoletje precej razširjena, zlasti za tiskane zbirke - vsebuje namreč tako glasbo za večernice kot tudi za mašo: psalme, magnifikate, himnuse in dve maši. ${ }^{20}$

Ko je Stivori leta 1602 postal organist v graški dvorni kapeli Ferdinanda II., so bile del repertoarja verjetno vsaj tri zbirke himnusov, zavedene v inventarju glasbenih instrumentov in muzikalij iz leta 1590, ${ }^{21}$ in sicer »Liber hymnorum Adriani Willart «, ${ }^{22}$ »Hymni Jacobi Vaet« ${ }^{23}$ in še »zwen Hymni« neimenovanega avtorja (ali več avtorjev). Univerzitetna knjižnica v Gradcu hrani zanimiv glasbeni rokopis, ki je nekoč pripadal tamkajšnjemu jezuitskemu kolegiju. ${ }^{24}$ Poleg drugih skladb obsega tudi himnuse Jacobusa Vaeta, Adriana Willaerta in doslej neidentificiranega skladatelja (gl. tabelo 1).

Federhofer je prikazal, da je bil repertoar graškega jezuitskega kolegija in dvora v veliki meri enak, kar je razumljivo, saj so v cerkvi sv. Egidija potekala bogoslužja tako dvora kot tudi jezuitov. ${ }^{25}$ Zato je prisotnost omenjenega repertoarja himnusov v MS 2064 nepresenetljiva.

Omenjeni rokopis kaže na to, da je bilo večglasno petje himnusov v Gradcu že prisotno in da so le-ti v zadnji četrtini 16. stoletja pravzaprav v veliki meri sledili t. i. italijanski liturgični tradiciji ciklusov himnusov. ${ }^{26}$ Willartov ciklus himnusov pripada italijanski tradiciji praznikov in besedil, vendar vsebuje nekatere himnuse, ki so značilni le za beneško liturgijo, kot je poudaril denimo Daniel Zager. ${ }^{27}$ Zato se najverjetneje v Gradcu niso peli vsi njegovi himnusi, temveč samo tisti, ki so ustrezali tamkajšnji liturgični praksi. Edini himnus, ki ne sodi v italijansko tradicijo, temveč v nemško, je A solis ortus cardine. ${ }^{28}$

${ }^{19}$ SI-Lnr, MS 343A, fol. 274-367; MS 343B, fol. 273-369. Več o kodeksu gl. npr.: Grabnar, »Parodične maše«, zlasti str. 42-72.

${ }^{20}$ Diplomatični prepisi naslovov vseh skladb v SI-Lnr, MS 343 so dostopni v: Grabnar, »Parodične maše«, 367-382.

${ }^{21}$ Gl. Federhofer, Musikpflege und Musiker, 287.

${ }^{22}$ Verjetno gre za zbirko Hymnorum musica secundum ordinem Romanae ecclesiae, natisnjeno leta 1542 (druga izdaja je bila tiskana leta 1550). Pet Willaertovih himnusov je sicer izšlo tudi v njegovi zbirki I sacri e santi salmi iz leta 1555 (ponatisnjena je bila leta 1565, v razširjeni različici pa je ponovno izšla leta 1571), nekaj pa se jih je ohranilo le v rokopisih. Gl. Weidensaul, »Polyphonic Hymns of Adrian Willaert«. Morda je bil z vključitvijo Willaertovega ciklusa himnusov v graški repertoar povezan Annibale Padovano, domnevno član Willaertove prestižne skupine učencev in vodja graške dvorne kapele.

${ }^{23}$ Po današnjem vedenju Vaetov opus obsega osem himnusov. Gl. Vaet, Sämtliche Werke, vol. 7.

${ }^{24}$ A-Gu, MS 2064.

${ }^{25}$ Federhofer, »Chorbücher der Universitätsbibliothek Graz«, 128-131.

${ }^{26}$ Ward, »Polyphonic Office Hymn«.

27 Zager, »Polyphonic Latin Hymns«, 54-55.

${ }^{28}$ Zanimivo je, da je glasbeni teoretik Lodovico Zacconi, nekaj časa zaposlen na dvoru Karla II. v Gradcu, Vaetov himnus A solis ortus cardine omenil v svojem traktatu Prattica di musica iz leta 1596. Prav mogoče je Zacconi omenjeni Vaetov himnus spoznal v Gradcu. Federhofer, »Chorbücher der Universitätsbibliothek Graz«, 132. 
Tabela 1

Himnusi v A-Gu, MS 2064

\begin{tabular}{|l|l|l|l|c|}
\hline Foliji & Skladatelj & Naslov & Liturgična priložnost & $\begin{array}{c}\text { Stevilo } \\
\text { glasov }\end{array}$ \\
\hline $27 \mathrm{v}-31 \mathrm{r}$ & $?$ & Ad cenam Agni providi & De gloriosa resurrectione Domini & 4,6 \\
\hline $43 \mathrm{v}-47 \mathrm{r}$ & $?$ & Lucis Creator optime & Diebus dominicis & $4-5$ \\
\hline $47 \mathrm{v}-53 \mathrm{r}$ & Jacobus Vaet & $\begin{array}{l}\text { Aurea luce et decore / Doctor } \\
\text { egregie }\end{array}$ & De SS Petro et Paulo & 5 \\
\hline $53 \mathrm{v}-58 \mathrm{r}$ & $?$ & Urbs beata Jerusalem & [Dedicatione ecclesiae] & $4-5$ \\
\hline $58 \mathrm{v}-62 \mathrm{r}$ & $?$ & Exsultet coelum laudibus & De apostolis & $4-5$ \\
\hline $62 \mathrm{v}-68 \mathrm{r}$ & Jacobus Vaet & Lauda mater Ecclesia & De S. Maria Magdalena & 5 \\
\hline $68 \mathrm{v}-74 \mathrm{r}$ & Jacobus Vaet & Ave maris stella & De b. virgine & $4-5$ \\
\hline $74 \mathrm{v}-78 \mathrm{r}$ & Jacobus Vaet & Deus tuorum militium & De uno martyre & $4-5$ \\
\hline $78 \mathrm{v}-83 \mathrm{r}$ & Jacobus Vaet & Iste cofessor & De confessoribus & $4-5$ \\
\hline $83 \mathrm{v}-90 \mathrm{r}$ & $?$ & Tibi Christe splendor & De S. Michaele archangelo & 5 \\
\hline $90 \mathrm{v}-97 \mathrm{r}$ & $?$ & $\begin{array}{l}\text { Christe redemptor omnium } \\
\text { conserva }\end{array}$ & De omnibus sanctis & $5-6$ \\
\hline $97 \mathrm{v}-101 \mathrm{r}$ & {$[$ Adrian Willaert] } & Jesu corona virginum & De virginibus & $4-5$ \\
\hline $101 \mathrm{v}-109 \mathrm{r}$ & Jacobus Vaet & Conditor alme siderum & In adventu Domini & $5-6$ \\
\hline $109 \mathrm{v}-119 \mathrm{r}$ & Jacobus Vaet & A solis ortus cardine & De nativitate et ephiphaniae Christi & 5 \\
\hline $119 \mathrm{v}-121 \mathrm{r}$ & $?$ & Audi benigne Conditor & In quadragesima & 4 \\
\hline $121 \mathrm{v}-123 \mathrm{r}$ & $?$ & Jesu nostra redemptio & De gloriosa ascensione Domini & 5 \\
\hline $123 \mathrm{v}-125 \mathrm{r}$ & $?$ & Veni creator Spiritus & In die Sancto Pentecostes & 5 \\
\hline $125 \mathrm{v}-127 \mathrm{r}$ & $?$ & 0 lux beata Trinitas & De SS Trinitate & 5 \\
\hline $127 \mathrm{v}-132 \mathrm{r}$ & Jacobus Vaet & Ut queant laxis & De S. Johanne baptistae & $4-5$ \\
\hline $133 \mathrm{v}-134 \mathrm{r}$ & $?$ & A solis ortus cardine & De nativitate Domini & 5 \\
\hline
\end{tabular}

Stivorijev nabor himnusov se skorajda ne razlikuje od tistega v MS 2064. Pravzaprav je najvidnejša razlika le v izboru himnusa za božič, in sicer je Stivori v skladu z italijansko tradicijo namesto A solis ortus cardine izbral himnus Christe redemptor omnium ex Patre.

Večernični himnusi Francesca Stivorija so namenjeni za vse večje praznike liturgičnega koledarja, od adventa dalje: ${ }^{29}$

1. Conditor alme siderum (In dominicis adventus Domini)

2. Christe redemptor omnium ex Patre (In nativitate et circumcisione Domini)

3. Salvete flores martyrum (In festo sanctorum innocentium)

4. Hostis herodes impie (In epiphania Domini)

5. Lucis creator optime (In dominicis diebus per annum)

6. Ad preces nostras (In dominicis diebus quadragesimae)

7. Vexilla regis prodeunt (In dominica passionis et festis S. Crucis)

8. Ad coenam agni providi (Ab octava paschae usque ad ascensionem)

9. Jesu nostra redemptio (In ascensione Domini)

${ }^{29}$ Ciklus je naslovljen: »Hymnorum per totius Anni | circulum Iuxta ritum | Sanctæ Romanæ | Ecclefiæ.|A. 8. | Francifcus Stiuorio.« 
10. Veni creator spiritus (In festo pentecostes)

11. O lux beata trinitas (In festo S. Trinitatis et diebus sabbathis)

12. Pange lingua gloriosi (In festo Corporis Christi)

13. Quodcunque vinclis (In cathedra S. Petri)

14. Doctor egregie (In conversione S. Pauli)

15. Ave maris Stella (In omnibus festi. B. M. V)

16. Ut queant laxis (In nativitate S. Ioannis Baptistae)

17. Aurea luce (In festo apostolorum Petri et Pauli)

18. Lauda mater Ecclesia (In festo S. Mariæ Magdalenæ)

19. Petrus beatus (In festo S. Petri ad vincula)

20. Quicunque Christum quaeritis (In festo transfigurationis Domini)

21. Tibi Christe splendor patris (In festo S. Michaelis Archangeli)

22. Christe redemptor omnium conserva (In festo omnium sanctorum)

23. Exultet coelum laudibus (In natali apostolorum)

24. Tristes erant apostoli (In communi aposto. et evange., tempore paschali)

25. Deus tuorum militum (In natali unius martyris)

26. Sanctorum meritis (In natali plurimorum martyrum)

27. Rex gloriose martyrum (In commu. plurimorum martyrum, tempore paschali)

28. Iste confessor (In natali confessorum)

29. Jesu corona virginum (In natali virginum et martyrum)

30. Huius obtentu (In festo sanctarum mulierum)

31. Urbs beata Jerusalem (In dedicatione ecclesise)

Pomenljivo je, da se izbor praznikov in besedil popolnoma ujema s tistim v Palestrinovi zbirki Hymni totius anni (1589), poleg tega si sledijo v enakem vrstnem redu. ${ }^{30}$ Nadalje je Stivori, tako kot Palestrina, svoj cikel zasnoval v praksi alternatim, in sicer je polifono uglasbil le lihe kitice besedil himnusov, ${ }^{31}$ kar je bilo redko; skladatelji so najpogosteje večglasno uglasbili sode kitice, lihe pa so se pele enoglasno. Tako se zdi, da je Palestrinova zbirka imela določen vpliv na Stivorijevo oblikovanje njegovega ciklusa himnusov. Enega izmed izvodov izvirnega tiska Palestrinovih himnusov hrani Univerzitetna knjižnica v Gradcu - ta je bil v nekem času najverjetneje del repertoarja graške dvorne kapele. Ali je Stivori spoznal Palestrinov ciklus himnusov v Gradcu ali že prej v Montagnani, ni jasno.

Stivorija se pogosto omenja kot predstavnika beneške skladateljske šole, ${ }^{32}$ vendar so njegovi principi formalnega oblikovanja dvozborja, kot se kaže na primeru himnusov, nekoliko enostavnejši in manj raznovrstni kot denimo tisti, ki jih lahko odkrivamo v glasbi Giovanija Gabrielija. V tem oziru bolj spominjajo na večzborsko glasbo nebeneških severnoitalijanskih skladateljev, na primer iz kroga Costanza Porte. ${ }^{33}$ Večina Stivorijevih himnusov je oblikovana s principi nerepetitivne antifonije in občasnih tutti odsekov.

\footnotetext{
${ }^{30}$ Palestrinova zbirka himnusov je izšla v Rimu in vsebuje poleg večerničnih tudi himnuse drugih oficijskih obredov.

${ }^{31} \mathrm{Na}$ začetku vsakega himnusa je enoglasna, koralna intonacija.

${ }^{32}$ Gl. na primer Gruber, »Stivori«, 684; Boisits, »Stivori«, 2314; Federhofer, »Stivori«.

${ }^{33}$ Več o kompozicijskih tehnikah pisanja za dva ali več zborov gl. v: Carver, Cori spezzati, zv. 1.
} 
Besedilni začetek vsake od uglasbenih kitic himnusov je praviloma dodeljen obema zboroma, enemu za drugim, z uporabo imitacije v vseh glasovih. Pri tem so uporabljeni motivi izpeljani iz koralne melodije. Le-ta je včasih bolj izrazita v enem izmed glasov, pogosto $v$ tenorju ali najvišjem glasu in večinoma poteka $v$ daljših notnih vrednostih kot v ostalih glasovih, vsaj na začetku vsake kitice. Nekatere notranje kitice himnusov so dodeljene le enemu zboru. Najnižja glasova obeh zborov sta na nekaterih mestih v razmerju kvinte - Stivori tako ne sledi tehniki skladanja za (strogo) ločene zbore (cori spezzati), kar je značilno za skladbe, namenjene graški dvorni kapeli.

Stivorijeva tiskana dela - z izjemo dveh tiskanih zbirk - so iz časa pred njegovim prihodom v Gradec. To je eden izmed razlogov za domnevo, da so njegove skladbe, ohranjene v rokopisih, iz Stivorijevega graškega obdobja. Nadaljnja razloga za to podmeno sta tudi, da so vsi rokopisni viri, v katerih so ohranjene njegove skladbe, graškega izvora, in da so te napisane za velike izvajalske zasedbe, ki so bile priljubljene na dvoru Ferdinanda II. v Gradcu.

Kot kažejo graški rokopisni viri iz konca 16. stoletja, stimul za nastanek Stivorijevega ciklusa himnusov ni bil sprejetje rimskega obreda v Gradcu, kot lahko denimo opazujemo na primeru münchenskega ciklusa izpod peresa Orlanda di Lassa. ${ }^{34}$ Večglasne uglasbitve himnusov, ki so se pele v Gradcu, namreč niso bile daleč od liturgične tradicije rimskega obreda, zato zamenjava celotnega ciklusa ni bila nujno potrebna. Potemtakem se zdi, da je Stivori svoj ciklus ustvaril, da bi ugodil nadvojvodi Ferdinandu, ki je bil zelo naklonjen večzborski glasbi. V času Stivorijevega delovanja v Gradcu je bilo večglasno petje samo lihih kitic himnusov morda že uveljavljeno, na kar namiguje zgoraj omenjeni obstoj Palestrinove zbirke. ${ }^{35}$ Omenjena tradicija polifonega petja lihih kitic je morala biti prisotna tudi kasneje na dvoru Ferdinanda na Dunaju, na kar kaže na primer rokopis s sredine Ferdinandovega vladanja kot Svetega rimskega cesarja s prepisom Palestrinovih himnusov. Zanimivo je, da se njihova besedila ujemajo s tistimi iz prvotnega tiska in ne z besedili popravljenega rimskega brevirja. Kot je ugotovil Steven Saunders, besedila himnusov na dunajskem dvoru niso sledila rimskemu obredu vse do leta 1637, ko so bili za ta namen predelani himnusi Tomása Luisa de Victorie. ${ }^{36}$

Stivorijev ciklus himnusov priča o močni tradiciji večzborske glasbe v Notranji Avstriji, zlasti na graškem dvoru, in predstavlja - skupaj z glasbo, ohranjeno v drugih graških rokopisih - pomemben prispevek k potridentinski katoliški kulturi.

\footnotetext{
${ }^{34}$ Zager, »Polyphonic Latin Hymns«, 12-13, 85.

${ }^{35} \mathrm{~V}$ tej zvezi velja omeniti tudi himnus Ave maris stella Ferdinandovega organista in kasneje vodje kapele Giovannija Valentinija, ki je prav tako uglasbitev samo lihih kitic. Izšel je v Valentinijevi zbirki Salmi, hinni, Magnificat, antifone, falsibordoni, et motetti concertati.

${ }^{36}$ Saunders, Cross, Sword, and Lyre, 52-53.
} 


\section{Viri in literatura}

\section{GLASBENI ROKOPISI}

Gradec, Universitätsbibliothek Graz (A-Gu), MS 2064.

Ljubljana, Narodna in univerzitetna knjižnica, Zbirka rokopisov, redkih in starih tiskov (SI-Lnr), MS 343.

\section{GLASBENI TISKI}

Antegnati, Costanzo. L'arte organica. Brescia: Francesco Tebaldino, 1608.

Artusi, Giovanni Maria. Seconda parte dell'Artusi overo delle imperfettioni della moderna musica. Benetke: Giacomo Vincenti, 1603.

Bellasio, Paolo. Il quinto libro de madrigali a cinque. Uredil Francesco Stivori. Verona: Francesco Dalle Donne, 1595.

Palestrina, Giovanni Pierluigi da. Hymni totius anni, secundum Sanctae Romanae Ecclesiae consuetudinem, quatuor vocibus concinendi. Rim: Giacomo Torniero \& Bernardo Donangelo (Francesco Coattino), 1589.

Stivori, Francesco. Ricercari a quatro voci. Benetke: Ricciardo Amadino, 1589.

___ Ricercari, capricci et canzoni a quattro voci [...] libro terzo. Benetke: Ricciardo Amadino, 1599.

___ Sacrae cantiones quaternis paribus voce decantandae; his accessit in fine missa, cum 2 Magnificat. Verona: Francesco Dalle Donne, 1595.

Valentini, Giovanni. Salmi, hinni, Magnificat, antifone, falsibordoni, et motetti concertati a una, due, tre, \& quattro voci con il basso per l'organo. Benetke: Giacomo Vincenti, 1618.

Willaert, Adrian, et al. Hymnorum musica secundum ordinem Romanae ecclesiae. Benetke: Gerolamo Scotto,1542.

-__- I sacri e santi salmi, che si cantano a Vespro et Compieta con li suoi himni, responsorii et Benedicamus (Benetke: Antonio Gardano, 1555).

\section{LITERATURA}

Anderson, Warren, Thomas J. Mathiesen, Susan Boynton, Tom R. Ward, John Caldwell, Nicholas Temperley in Harry Eskew. »Hymn«. V: Grove Music Online. Obiskano 10. oktobra 2017. https://doi.org/10.1093/gmo/9781561592630.article.13648.

Boisits, Barbara. »Stivori, Francesco«. V: Oesterreichisches Musiklexikon, uredil Rudolf Flotzinger, 5:2314. Dunaj: Verlag der Österreichischen Akademie der Wissenschaften, 2006.

Carideo, Armando. »Wiederentdeckte Kompositionen von Francesco Stivori und Germano Pallavicino«. Basler Jahrbuch für Historische Musikpraxis 22 (1998): 53-67.

Carver, Anthony F. Cori spezzati. 2 zv. Cambridge: Cambridge University Press, 1988.

Eitner, Robert. Biographisch-Bibliographisches Quellen-Lexikon der Musiker und Musikgelehrten christlicher Zeitrechnung bis Mitte des neunzehnten Jahrhunderts. 2. dopolnjena izd. Gradec: Akademische Druck- u. Verlagsanstalt, 1959.

Federhofer, Hellmut. »Chorbücher der Universitätsbibliothek Graz in ihrer Beziehung zur Grazer Hofkapelle (1564-1619)«. V: Musikalische Quellen - Quellen zur 
Musikgeschichte: Festschrift für Martin Staehlin zum 65. Geburtstag, uredil Ulrich Konrad, 127-139. Göttingen: Vandenhoeck \& Ruprecht, 2002.

___ _ „ „Graz Court Musicians and Their Contributions to the "Parnassus musicus Ferdinandaeus” (1615)«

-_- Musikpflege und Musiker am Grazer Habsburgerhof der Erzherzöge Karl und Ferdinand von Innerösterreich (1564-1619). Mainz: B. Schott’s Söhne, 1967.

____. Musik und Geschichte: Aufsätze aus nichtmusikalischen Zeitschriften. Hildesheim: Georg Olms Verlag, 1996.

____ „ „Stivori, Francesco«. V: Grove Music Online. Obiskano 10. oktobra 2017. https:// doi.org/10.1093/gmo/9781561592630.article.26795.

Grabnar, Klemen. »Parodične maše v Hrenovih kornih knjigah«. Doktorska disertacija, Univerza v Ljubljani, 2015.

Gruber, Gernot. »Stivori, Francesco«. V: Suppan, Wolfgang, Steirisches Musiklexikon, 2. izd, 684-685. Graz: Akademische Druck- u. Verlagsanstalt, 2009.

Höfler, Janez. Glasbena umetnost pozne renesanse in baroka na Slovenskem. Ljubljana: Partizanska knjiga, Znanstveni tisk, 1978.

Kokole, Metoda. »From Graz to Today's Central Slovenia: The Influence of Italian Polychoral Music in the Period c. 1595 to c. 1620«. V: La musica policorale in Italia e nell'Europa centro-orientale fra Cinque e Seicento / Polychoral Music in Italy and in Central-Eastern Europe at the Turn of the Seventeenth Century, uredili Aleksandra Patalas in Marina Toffetti, 335-374. TRA.D.I.MUS., Studi e monografie, 1. Benetke: Edizioni Fondazione Levi, 2012.

Refatti, Nicola. »Vorwort«. V: Francesco Stivori, Madrigali a tre voci (1590), uredil Nicolas Hémard, viII. Liergues: Éditions de l'AME, 2014.

Saunders, Steven. Cross, Sword, and Lyre: Sacred Music at the Imperial Court of Ferdinand II of Habsburg (1619-1637). Oxford: Clarendon Press, 1995.

Vaet, Jacobus. Sämtliche Werke. Vol. 7, Hymnen und Chansons. Uredil Milton Steinhardt. Denkmäler der Tonkunst in Österreich, 118. Gradec: Akademische Druck- u. Verlagsanstalt, 1968.

Ward, Tom Robert. »The Polyphonic Office Hymn from the Late Fourteenth Century until the Early Sixteenth Century«. Doktorska disertacija, University of Pittsburgh, 1969.

Weidensaul, Jane Bennett. »The Polyphonic Hymns of Adrian Willaert«. Doktorska disertacija, Rutgers, The State University of New Jersey, 1978.

Zager, Daniel Arthur. »The Polyphonic Latin Hymns of Orlando di Lasso: A Liturgical and Repertorial Study«. Doktorska disertacija, University of Minnestota, 1985. 


\section{A LITTLE-KNOWN DOUBLE-CHOIR HYMN CYCLE FROM c. 1600}

\section{Summary}

SI-Lnr, MS 343 - an early seventeenth-century codex in two volumes from a collection of six well-preserved choirbooks of Graz origin known today as the Hren choirbooks, today preserved in Ljubljana - contains psalms, Magnificat settings, hymns and Masses for eight to fourteen voices. There are thirty-seven unica present in this manuscript, among them a complete cycle of Vespers hymns for the liturgical year (thirty-one in number) by Francesco Stivori (c. 1550-1605). Stivori, probably a pupil of Claudio Merulo and a close friend of Giovanni Gabrieli, was from 1579 to 1601 the organist at Montagnana, near Padua. In 1602 he became an organist at the court of Archduke Ferdinand of Inner Austra, a post he held until his death.

Stivori's hymns were intended for all major feasts of the liturgical calendar, starting with Advent. It is noteworthy that the feasts and texts correspond exactly to those in Palestrina's collection of 1589 (except that Palestrina included also hymns for other Office hours); also, they are laid out in a similar way. Like Palestrina, Stivori composed his cycle in accordance with strict alternatim practice, setting polyphonically only the odd-numbered stanzas of the texts. Thus the first line of text for each strophe is sung to the plainchant melody, the polyphonic setting beginning with the second line. It is significant that a copy of the original print of Palestrina's hymn collection is preserved in the Universitätsbibliothek in Graz - this source may well originate from the Graz court repertory. However, it is unclear in what circumstances Stivori become acquainted with Palestrina's hymns in Graz or elsewhere.

Stivori is often cited as a representative of the Venetian school of composers - this despite the fact that the formal design of Stivori's hymns is somewhat simpler and less varied than that of, for instance, Giovanni Gabrieli's compositions. The majority of Stivori's hymns consist of non-repetitive antiphony for the first two lines of each hymn strophe set to music; the textual beginning of the first two lines of the hymn (or of the second and third lines in the first strophe) is usually given to the two choirs in succession, each in a polyphonic, imitative way where motifs from the plainchant appear in all of the voices in points of imitation. The plainchant melody is more prominent in one of the voices, often in somewhat longer values than in the other parts, at least at the beginning of each strophe. The next line is as a rule marked by an extensive use of tutti writing, this then (in the last line) being followed by a series of antiphonal repetitions of shorter phrases, often transposed, leading into the final tutti. This scheme can be varied to some extent. In some of the hymns only one choir is used for internal strophes. In all these respects Stivori's hymns are reminiscent of polychoral music in Northern Italy outside Venice.

As the Graz manuscripts from the late sixteenth century show, the stimulus for Stivori's hymn cycle was not, for example, the acceptance of the Roman rite in Graz. Polyphonic hymn settings used earlier at the Graz court were, therefore, not rendered liturgically obsolete in such a way as to necessitate Stivori's new collection. It seems, rather, that Stivori composed his own cycle - probably one of the first polychoral cycle of hymns written - to cater for the personal needs of Archduke Ferdinand, who greatly favoured polychoral music. 